\section{Bionomics of a Cattle Louse}

IN the course of a study of the life-histories and bionomics of cattle lice, I have found that the species Solenopotes capillatus, End., hitherto considered to be rare in Great Britain, is more common than has been supposed. I found the species first on dairy shorthorn cattle (cows, heifers and calves) at the Cooper Field Research Station, Little Gaddesden, Herts, and further investigations in the neighbourhood revealed the presence of this louse on three other farms. It thus appears that there is a high incidence of $S$. capillatus in Hertfordshire.

While engaged on field work in Scotland in April of this year, I was able to find these lice on cattle at three out of a total of seven farms, where I made examinations. This, I believe, is the first record of the occurrence of $S$. capillatus in Scotland. The localities of the three farms were Strathyre, Perthshire, and Bentpath and Langholm, Dumfriesshire.

These records prove to be more interesting when it is added that examinations conducted on thirteen farms disclosed the presence of Bovicola bovis on eleven, Hoematopinus eurysternus on eight, Linognathus vituli on five and Solenopotes capillatus on seven. The species of sucking lice were confined to nine only of the thirteen farms, which fact signifies a relatively high incidence of $S$. capillatus. With a single exception, the infested cattle were all dairy shorthorns, and the parasites were found on both sexes of all ages, that is, bulls, cows, heifers, bullocks and calves.

The original record and description of $S$. capillatus was made by Enderlein ${ }^{1}$ in Germany. Bishopp ${ }^{2}$ recorded the species in the United States, where this louse appears to be widely distributed. The earliest record of the occurrence of the species in England (Cornwall) appears to be that of Noel Pillers ${ }^{3}$. Australian records are those of O'Connor' (Perth, W. Australia) and McCulloch and Noble ${ }^{5}$ (New South Wales). Freund ${ }^{6}$, who redescribed this insect in Germany, gives a detailed description of the external anatomy, comparing his observations with those of Bishopp.

The available evidence suggests that $S$. capillatus is widely distributed, and is possibly more important than has been supposed, and, further, that this louse should be included with the other three well-known species attacking cattle, when considering control measures.

Cooper Technical Bureau,

H. J. Craufurd-Benson.

47 Russell Square,

London, W.C.1.

May 2.

1 Enderlein, Zool. Anz., 28, 144 (1904).

2 Bishopp, J. Agric. Res., 21, 797 (1921).

${ }^{3}$ Pillers, Vet. J., 79, 162 (1923).

' O'Connor, J. Dept. Agric. W. Aust., 9, 300 (1932).

- MeCulloch and Noble, Agric. Gaz. N.S.W., 44, 10 (1933).

- Freund, Prager Arch. Tiermed., '7, 215 (1927).

\section{Succession in Birthcoat Kemp Follicles}

DR. A. B. WILDMAN ${ }^{1}$, communicating the findings of the late Prof. J. E. Duerden, has recently written about the nature of the successors of birtheoat kemp in the merino, pointing out especially that an original kemp is sometimes followed, in the same follicle, by a fine non-medullated fibre.

In dissections of Romney skin taken about ten weeks after birth, a hair-cone has been found below a club-hair birthcoat kemp. In 1931 at this College, Miss Anthea Hefford showed, among other facts about sweat glands, that the follicle of a birtheoat kemp always possessed a sweat gland, but not so the newly developed follicle of a fibre added to the fleece in the early months after birth. At ten weeks, follicles with sweat glands were found with the tip of a new fibre just protruding from the wide mouth of the follicle. New fibres, similarly short, in follicles lacking sweat glands, were closely gripped by the sheath surrounding the emerging tip. At three months, non-medullated fibres, an inch or a half or so shorter than the long persistent birthcoat fibres, were found in follicles with sweat glands attached. The freedom from medulla of the successors of birthcoat kemps is brought home on examining in the benzol tray specimens from certain covered lambs in which the shed birthcoat kemps stand out at the tip of the staple, while below there is no medulla at all, or just a touch of it in the apical ends of fibres far fewer than the birthcoat kemps.

Differences in the nature of the successors $\left(G_{2}\right)$ of birthcoat kemps $\left(G_{1}\right)$ have been studied, especially on the middle of the back at the level of the attach. ment of the last $\mathrm{rib}^{2}$. For simplicity attention may be focused upon the successors of the largest birthcoat kemps, the halo-hairs, in fibre type arrays containing sickle-fibres, although a parallel story could be related for the 'plateau array', which, typically, lacks sickle-fibres. Amongst the immediate successors $\left(G_{2}\right)$ of halo-hairs the presence of a big proportion of kemps is correlated with the shedding of a substantial majority, usually threequarters or more, of the large-ended sickle-fibres. Reasons have been pub. lished for attributing the shedding of kemp to vigour on the part of the follicle.

When there is little $G_{2}$ kemp, it has been concluded that the hairiness (medullation) of the persistent successors can, in some measure, be correlated with degree of freedom of shedding of the large-ended sickle-fibres, but that the medullation of these successors tends also to reflect that of large persistent birthcoat fibres, the curly-tip fibres.

Following the $G_{2}$ 'crop' of kemp there may be another, or even two more crops of secondary kemps grown before the first shearing at some fourteen months. Such later kemp has been found in any abundance only in lambs in which the fibre type array is 'saddle', or a near approach to that array. Such an array is indicative of a mild pre-natal check. In the 'valley array' the pre-natal check is intense. In this array there is much $G_{2}$ kemp if halo-hairs are abundant and the large-ended sickle-fibres shed freely, but there is little later kemp $\left(G_{3}\right.$ and $\left.G_{4}\right)$. The consequences of a pre-natal event are reaped, it is thus concluded, at the age of nine months.

Preliminary breeding experiments point to genetic factors being of importance in determining the above differences in the 'kemp history' of the fleece of the first year.

Not only does theoretical trichology have practical significance in wool production, but also that somewhat large domesticated animal, the sheep, grows good material for pure zoology.

Massey Agricultural College,

F. W. DRY.

Palmerston North,

New Zealand. April 1.

1 NATURE, 140, 893-94 (Nov. 20, 1937).

' N.Z. J. Agric., 48 (June 1934). 